478) gives the impression that both populations were known to be drawn from the same area.

The selection of the mining population by panel attendance and death imposes an inevitable and strong bias and leaves unknown the population of living miners and ex-miners (with or without pneumoconiosis) from the same decades and areas of the deceased miners and ex-miners. The absence of an age gradient of emphysema in the mining group compared with the contrast group would seem to confirm this bias. The explanation given that confluent fibrotic lesions may have obscured emphysema is improbable as no gradient in men with category " $O$ " to " $A$ " was demonstrated. This point has also been commented on by Dr. C. M. Fletcher (17 October, p. 176).

We cannot accept that the difference in the prevalence of emphysema found to exist between the miners and the contrast population is representative of the real difference between miners as a whole and the general population. Nor do we think the authors have demonstrated an excess of any particular type of emphysema among the miners with pneumoconiosis.-We are, etc.,

W. Raymond Parkes.

R. G. B. Williamson.

T. J. G. Phillips.

London W.C.2.

REFERENCE

1 Reid, L, The Pathology of Emphysema, p. 329, London, Lloyd-Luke, 1967.

\section{Maternal Phenylketonuria}

SIR,-I welcome your leading article (24 October, p. 192) encouraging us to screen for phenvlketonuria in the antenatal clinic. I would like to take the argument one stage further and come down in favour of ferric chloride or Phenistix urine testings as part of the routine urine examination in the antenatal clinic, rather than using a blood test, which takes longer, costs more, and tells us less. Auerbach ${ }^{1}$ has ingeniously shown from a study of reported cases that a positive urine test separates the mothers with phenylketonuria whose babies are at risk from those that are safe better than blood levels of phenylalanine-which, as you point out, are not a good guide. At least two cases have been described, one in North America and one here, ${ }^{2}{ }^{3}$ where undiagnosed mothers with phenylketonuria have been picked up by routine antenatal Phenistix, in one of which ${ }^{3}$ a low phenylalanine diet during pregnancy similar to that described by Allan and Brown $n^{4}$ resulted in the birth of a child with normal intelligence.-I am, etc.,

Derbyshire Children's Hospital,

$$
\text { L. J. H. ARThur. }
$$

Derby.

\section{REFERENCES}

1 Auerback, V. H., in Amino Acid Metabolism and Genetic Variation. ed. W. L. Nyhan, p. 65, New
York, McGraw-Hill, 1970. York, McGraw-Hill, 1970.

and Gynaecology, 1969, 34, 694.
and

3 Arthur, L. J. H., and Hulme, J. D., Pediatrics,

4 Allan. T. D.. and Brown, J. K. in Some Recent Advances in Inborn Errors of Metabolism, ed.
K. S. Holt and V. P. Coffey, p. 14. Edinburgh,
Livingstone, 1968.

\section{Gangrene of Digits}

SIR,-The case report by Dr. O. H. B. Gyde and Dr. D. L. Beales (31 October, p. 284 ) is of great interest and bears a strong similarity to our description of three African children with bilateral symetrical gangrene. These three patients presented with gangrene of the finger tips despite the presence of patent digital arteries. No predisposing factors were apparent and we could not elicit any history of previous virus infection.

Investigation of the coagulation mechanism revealed no abnormality but there was significant depression of spontaneous plasma fibrinolytic activity as compared with age- and sex-matched controls. This finding has been described previously ${ }^{2-4}$ in patients with widespread thrombotic disease. Histological examination of postmortem material from one of our patients showed thrombus in a vein draining the gangrenous area.

The basic disorder in such patients is not clear and it may be that the changes described by us were "effect" rather than "cause." However, the presence of organizing thrombus in the patient reported by $\mathrm{Dr}$ Gyde and Dr. Beales and in one of ours would suggest that a trial of fibrinolytic enzymes (streptokinase) given early in the evolution of the disease process would be of value.-We are, etc.,

\section{Charles D. Forbes.} G. P. MCNICOL.

University Department of Medicine. Royal Infirmary,

REFERENCES

1 Turpie, A. G. G., Forbes, C. D., and McNicol, G. P., British Medical Fournal, 1967, 3, 646. Soderberg, E., and Soderstrom, N., Acta M. H. Scandinavica, $1961,169,323$.

Nilsson, I. M., Nilehn, J.-E., Cronberg, S., and Norden, G., Acta Medica Scandinavica, 1966

Brackman, P., Mohler, E. R., and Astrup. T.,
Scandianavian fournal of Haematology, 1966, 3, 389.

\section{Continuous Ventilation and Oedema}

SIR,-Dr. J. M. K. Spalding (12 September, p. 645) asks if our patient who developed marked oedema while on long continued intermittent positive-pressure ventilation was underventilated during weaning. We regret if we did not make it clear that there was no attempt at weaning our patient off the ventilator. The patient has a permanent loss of all respiratory muscular activity because of her myasthemia gravis. We are unable to give details of her airway pressure during the first nine years of her treatment as she was not under our care at that time. When she was tansferred to our care she was on positive-pressure ventilation using a Barnet Mark II as a time-cycled minute volume divider. The minute volume was 8 litres, rate 13 , inspiratory time 1 second, and the maximum positive inspiratory pressure $15 \mathrm{~cm}$. water. A subatmospheric expiratory phase was introduced without any other alteration to the setting of her ventilator. The oedema resolved but when the subatmospheric expiratory phase was withdrawn the oedema reappeared. The oedema again disappeared when several days later the subatmospheric expiratory phase without any other change to ventilation was reintroduced.
Since the only change made in this patient was the introduction of a subatmospheric expiratory phase and this was associated with regression of the oedema we were naturally interested, particularly as the reduced lung volume consequent upon the subatmospheric phase reduced the lung compliance and caused the peak airway pressure to rise to $20 \mathrm{~cm}$. $\mathrm{H}_{2} \mathrm{O}$ when the inspiratory time was held constant.

The fact that it was repeatable in our patient led us to ask if anybody has observed anything similar in patients who have been on continued intermittent positive-pressure ventilation over a long period.-We are, etc.,

J. T. STyles.

P. J. TOMLIN.

Department of Anaesthetics,
Queen Elizabeth Hospital, Birmingham.

\section{Prophylactic Lithium}

SIR, - I was most interested to read your recent leading article (29 August, p. 479) on the prophylactic use of lithium carbonate. The published evidence in support of its therapeutic action is steadily increasing, but, as you so rightly comment, these results must be interpreted with great caution at this early stage of assessment. Since, however, the initial successes are stimulating an ever wider use of this salt it is most important that the method of determining the correct dosage be crystal clear. Unfortunately this particular issue remains clouded as many leading authors give conflicting advice.

The primary aim should be to keep the serum lithium level between 0.8 and 1.6 $\mathrm{mEq} / 1 .^{1} \mathrm{~A}$ lower level of $0.6-0.8 \mathrm{mEq} / \mathrm{l}$. is acceptable if a higher one causes intolerable side effects. ${ }^{12}$ The dose of lithium salt reauired to achieve the therapeutic serum level is quite unpredictable except by the regular monitoring of the blood. A variation in the serum lithium level from a constant daily dosage might be expected to coincide with mood change, since it has been shown that lithium retention in the body was greater in manic patients than when they were normothymic. ${ }^{35}$

In my own group of patients it was found that. on average, a stable serum level was obtained by the third week. Once achieved it was maintained in the majority of patients for long periods, although in two patients there was a sudden change to a new higher stable level without any apparent clinical reason. Venepuncture was carried out every six weeks: this proved satisfactory from both the clinical and patient's points of view. It is important to know that after taking lithium orally there follows a peak rise in the serum level which is auite unpredictable in both magnitude and duration. It is therefore quite unreliable to calculate the dosage of medication on a serum level where oral medication has been taken in the preceding eight hours. The occurrence of a peak rise has a further importance, since my own observations suggest that certain side effects, particularly gastrointestinal, have a close association with the height and duration of the elevated serum lithium level. Other authors ${ }^{6-8}$ have also shown that the less serious side effects are related to the serum level of lithium, even within the therapeutic range $(0.8-1.6$ 